\title{
Differential Effects of Alternative Glycoforms of IgG on Human Monocytes and Macrophages: Sialylated IgG Induces Novel Expression Signatures of Cell Surface Markers, Cytokines, and Chemokines
}

\author{
Eric D. Bruder, John O. Richards, Karen M. Michel, Martin Oaks \\ Transplant Research Laboratory, Aurora St. Luke's Medical Center, Milwaukee, WI, USA \\ Email: martin.oaks@aurora.org
}

Received 13 April 2016; accepted 6 June 2016; published 9 June 2016

Copyright (C) 2016 by authors and Scientific Research Publishing Inc.

This work is licensed under the Creative Commons Attribution International License (CC BY).

http://creativecommons.org/licenses/by/4.0/

(c) (i) Open Access

\section{Abstract}

The effector functions elicited by the fragment crystallizable (Fc) region of immunoglobulin G (IgG) antibodies are subject to variation by the presence of terminal sialic acid (Sia) residues at asparagine-297 (Asn-297). We have previously shown that the sialic acid-containing (Sia ${ }^{+}$) fraction of intravenous immune globulin (IVIG) influences cell surface marker expression and cytokine/chemokine secretion during the differentiation and maturation of human dendritic cells (DC). The present study examined the effects of $\mathrm{Sia}^{+}$IgG on human peripheral blood mononuclear cell (PBMC)-derived monocyte and macrophage surface marker expression and cytokine/chemokine secretion. Sia ${ }^{+}$IgG induced increased expression of CD80 and dendritic cell immunoreceptor (DCIR) on monocytes, whereas the expression of HLA-DR was decreased. In addition, the production of IL-6, TNF $\alpha$, IL-1 $\beta$, and CXCL1 by monocytes was profoundly increased by treatment with $\mathrm{Sia}^{+}$IgG. Sia ${ }^{+}$IgG also increased the expression of cell surface markers associated with macrophage polarization (e.g. CD40 and CD206) on monocytes. In macrophage-colony stimulating factor (MCSF) generated macrophages, $\mathrm{Sia}^{+}$IgG induced increased production of numerous cytokines/ chemokines including IL-6, TNF $\alpha$, CXCL1, and IL-10, and the expression of the macrophage surface marker CD163. Our data extended prior observations of Sia' IgG on DC function and showed that $\mathrm{Sia}^{+}$IgG was able to differentially modulate multiple pathways in monocytes and macrophages. Our data indicate that the $\mathrm{Sia}^{+}$fraction of IVIG possesses the ability to influence inflammatory processes in multiple immune cell types and induces novel signatures in cell surface marker expres-

How to cite this paper: Bruder, E.D., Richards, J.O., Michel, K.M. and Oaks, M. (2016) Differential Effects of Alternative Glycoforms of IgG on Human Monocytes and Macrophages: Sialylated IgG Induces Novel Expression Signatures of Cell Surface Markers, Cytokines, and Chemokines. Open Journal of Immunology, 6, 49-62. 
sion and cytokine/chemokine production.

Keywords

Anti-Inflammatory, IgG, IVIG, Monocytes, Macrophages, Sialic Acid

\section{Introduction}

It has long been known that the fragment crystallizable $(\mathrm{Fc})$ region of the immunoglobulin $\mathrm{G}(\mathrm{IgG})$ molecule elicits different effector functions on immune and inflammatory cells [1] [2], and that these functions are strongly influenced by the N-linked glycan structure at asparagine-297 (Asn-297) [3] [4]. Previous studies have shown that sialic acid-containing $\left(\mathrm{Sia}^{+}\right) \mathrm{IgG}$ is responsible for the potent anti-inflammatory properties of intravenous immune globulin (IVIG), even though it represents only a small fraction (1-10\%) of the total IgG [1] [5]. $\mathrm{Fc}$ binding to inhibitory $\mathrm{Fc}$ receptors mediates these different effector functions at the level of a variety of immune cell populations, including lymphocytes and cells of the monocyte/macrophage/dendritic cell (DC) lineages [6]-[8].

Monocytes are central to the promotion, mediation, and resolution of inflammatory reactions and represent a pool of circulating precursors that can differentiate into DC or macrophages [9]-[11]. Such developmental flexibility is retained until the late stages of differentiation. DC plays a critical role in both $\mathrm{T}$ cell priming and $\mathrm{T}$ cell tolerance [12], and macrophages are strategically located throughout the body tissues, where they ingest and process foreign materials, dead cells and debris, and recruit additional macrophages in response to inflammatory signals [11] [13] [14]. Monocytes are a highly heterogeneous population of cells that can rapidly change their function in response to local micro-environmental signals [14]. Macrophages have been described as having the ability to polarize towards inflammatory (M1), anti-inflammatory (M2), or regulatory phenotypes [15] [16]; however, a precise phenotype for each function has not been adequately described [17] [18]. It has been recently suggested that macrophage characterization should not be based on a distinct phenotype, but rather on functionally distinct actions elicited by external signals (e.g. cytokines/chemokines or immunoglobulins) [17] [19].

Our laboratory has previously shown that patients with melanoma and breast cancer often develop a population of antibodies that may have anti-inflammatory properties [20]. In the setting of cancer, instead of eliciting effector pathways that would lead to tumor elimination, these antibodies might promote down-regulation of the cellular inflammatory responses to the tumor. In addition, these antibodies may modulate regulatory pathways, including regulatory T-cells and/or myeloid-derived suppressor cells. We have shown that antibodies to the NYESO-1 tumor antigen were a common finding in metastatic melanoma, belonging to the IgG class, and were commonly associated with the glycan signature within the Fc region of IgG that terminates in $\alpha 2,6$-linked sialic acid (Sia) [20]. We subsequently characterized some of the functional activities of $\mathrm{Sia}^{+}$antibodies versus antibodies that contained little or no Sia residues ( $\mathrm{Sia}^{-}$) on human DC differentiation and maturation [21]. Our results show that these different populations of antibodies vary in their ability to modulate the expression of messenger ribonucleic acid (mRNA) of a variety of cytokines, chemokines, and cell surface receptors on DC. We also found that $\mathrm{Sia}^{+} \mathrm{IgG}$ antibodies elicited a profound increase in the secretion of the melanoma growth factor CXCL1 during DC differentiation. These findings suggested that $\mathrm{Sia}^{+} \mathrm{IgG}$ could modulate the inflammatory response through multiple mechanisms. As an extension of this work, we hypothesized that $\mathrm{Sia}^{+} \mathrm{IgG}$ may also modulate the effector functions of other inflammatory cells, namely monocytes and macrophages. The current study examined the effects of unfractionated IVIG, and Sia-enriched $\left(\mathrm{Sia}^{+}\right)$, and Sia-depleted ( $\left.\mathrm{Sia}^{-}\right) \mathrm{IgG}$ on human monocyte and macrophage generation and activation. We employed flow cytometry to analyze cell surface markers commonly expressed on monocytes and macrophages and also measured cytokine/chemokine concentrations in cell supernatants from the various treatment groups. The results expanded our prior data on DC function and showed that $\mathrm{Sia}^{+} \mathrm{IgG}$ was able to differentially modulate multiple pathways in peripheral blood mononuclear cell (PBMC)-derived monocytes and macrophages. The current data also confirm that alternate glycoforms of IgG have profound differential effects on inflammatory cell phenotype and function. The complex mechanisms of the response of inflammatory cells to IVIG appear to represent a balance of both inhibitory and stimulatory signals that can be dissected on the basis of variation of $\mathrm{Fc}$ glycosylation. 


\section{Materials and Methods}

\subsection{Isolation of Monocytes from Peripheral Blood Mononuclear Cells}

Human PBMC collected from Leukopaks were obtained from Hemacare Corporation (Van Nuys, CA). Experiments reported herein were performed on freshly isolated PBMC ( $<36 \mathrm{~h}$ old $)$ from a total of fourteen separate donors. PBMC were processed using the Human Monocyte Enrichment Kit without CD16 Depletion (StemCell Technologies, Vancouver, BC, Canada) according to the manufacturer's instructions. The suspension containing freshly isolated monocytes was centrifuged and the pellet was re-suspended in tissue culture media (TCM: DMEM; 10\% FBS; $1000 \mathrm{U} / \mathrm{mL}$ penicillin; $1000 \mathrm{U} / \mathrm{mL}$ streptomycin; $1 \mu \mathrm{g} / \mathrm{mL}$ gentamicin). Cells were counted via trypan blue exclusion and diluted with TCM to the appropriate concentration needed for each culture experiment. Monocyte preparations were routinely $>90 \% \mathrm{CD}_{1} 4^{+}$as determined by flow cytometry. In order to minimize the interaction of bovine IgG on effector cells, a source of FBS that contained ultra-low levels of IgG (\#16250-078, Life Technologies, Grand Island, NY) was used throughout the course of this work.

\subsection{Fractionation of IVIG}

IVIG (Privigen 10\%: CSL Behring LLC, Kankakee, IL) was used intact or fractionated by sambucusnigra (SNA) lectin chromatography essentially as previously described [21]. IgG from both SNA fractions (positive and negative) were further purified on Protein A/G columns (Pierce Immunochemical, \#89950, Rockford, IL) to avoid carryover of free SNA lectin. In our hands, this preparation consisted of $12.5 \% \mathrm{Sia}^{+}$material and $87.5 \%$ $\mathrm{Sia}^{-}$(data not shown) which is consistent with previous reports [1] [5] [22]. The starting concentration of Sia ${ }^{+}$ material $(125 \mu \mathrm{g} / \mathrm{mL})$ for the culture experiments was based on optimization of the effect on DC function described previously [21]. The $\mathrm{Sia}^{-}$fraction was therefore used at $875 \mu \mathrm{g} / \mathrm{mL}$ as a comparator to $1000 \mu \mathrm{g} / \mathrm{mL} \mathrm{intact}$ IVIG.

\subsection{Monocyte Culture and Treatment with Different IgG Glycoforms}

Monocytes were plated at 25,000 - 100,000 cells/well in 96-well polypropylene plates (CoStar@, Corning Life Sciences, Tewksbury, MA). The volume of each well was brought up to $200 \mu \mathrm{L}$ with TCM containing no IgG, IVIG, the $\mathrm{Sia}^{+}$fraction of IVIG, or the $\mathrm{Sia}^{-}$fraction of IVIG. The cultures were incubated at $37^{\circ} \mathrm{C}$ and $5 \% \mathrm{CO}_{2}$ (in air) for $48 \mathrm{~h}$. Initial optimization experiments included titration of the $\mathrm{Sia}^{+}$fractions compared to fixed doses of IVIG $(1000 \mu \mathrm{g} / \mathrm{mL})$ and $\mathrm{Sia}^{-}(875 \mu \mathrm{g} / \mathrm{mL})$. All treatments for each plate were performed in triplicate. Cellfree culture supernatants were stored at $-80^{\circ} \mathrm{C}$ for cytokine/chemokine analyses. Cells were then processed for flow cytometry as outlined below.

\subsection{Macrophage Generation and Treatment with Different IgG Glycoforms}

Monocytes were cultured with macrophage-colony stimulating factor (M-CSF) (1000 IU/mL; R\&D Systems, Minneapolis, MN) for six days at a concentration of $1.0 \times 10^{6}$ cells $/ \mathrm{mL}$, after which both adherent and non-adherent cells were collected. Adherent cells were obtained by detachment with lidocaine in TCM $(4 \mathrm{mg} / \mathrm{mL}$; Sigma, St. Louis, MO). All incubations were done in 24 -well culture plates containing $2.0 \times 10^{5}$ cells/well. Cells were treated with IVIG or its fractions and harvested following $48 \mathrm{~h}$ incubation. Cell-free supernatants from each well were frozen for cytokine/chemokine analyses. Both adherent and non-adherent cells were pooled and stained for flow cytometry as described below.

\subsection{Flow Cytometry}

Direct flow cytometry stains were used to determine if the different IgG glycoforms influenced the expression of common monocyte or macrophage cell-surface antigens. Approximately $1 \times 10^{5}$ cells were stained in a total volume of $100 \mu \mathrm{L}$ in BSA Staining Buffer (BD Biosciences, San Jose, CA). All antibodies were purchased from BD Biosciences. For the monocyte panel, cells were stained with anti-HLA-DR (Clone G46-6), anti-CD86 (Clone 2331(FUN-1)), anti-CD209 (DC-SIGN) (Clone DCN46), anti-CD80 (Clone L307.4), and anti-DCIR (Clone CLEC4A; R\&D Systems). For the macrophage panel, cells were stained with anti-CD40 (Clone 5C3), anti-CD64 (Clone 10.1), anti-CD163 (Clone GHI/61), or anti-CD206 (Clone 19.2). This panel was representative of those commonly reported to best define M1 and M2 polarized macrophages [23]-[26]. Stained cells were 
analyzed on a LSR Fortessa (BD Biosciences), and data analyses were performed with the accompanying FACSDiva software.

\subsection{Cytokine and Chemokine Measurement in Cell Supernatants}

Concentrations of IL-6, IL-2, IL-1 $\beta$, TNF $\alpha$, RANTES, IL-10, MCP-4, and CXCL1 were analyzed using the Magnetic Luminex ${ }^{\circledR}$ Screening Assay according to the user manual (R\&D Systems, Minneapolis, MN). Measurements were made using the Luminex ${ }^{\circledR} 200^{\mathrm{TM}}$ system (Invitrogen, Grand Island, NY) and data were analyzed with the XPONENT 3.1 software package. TGF- $\beta 1$ and IL-4 were measured by ELISA according to the manufacturer's instructions (R\&D Systems). The selection of cytokines/chemokines for analyses was based on expression profiles of mRNA and secreted proteins from DC described previously by our laboratory [21].

\subsection{Statistical Analyses}

Data analyses were performed using the SigmaStat (version 2.03) software package. Comparisons between groups were made by One-way Analysis of Variance (ANOVA). Post-hoc analysis was performed using the Student-Neuman-Keuls method. $\mathrm{P}<0.05$ was considered a significant difference between treatment groups. Data are presented as the mean \pm SEM.

\section{Results}

\subsection{Sia ${ }^{+}$IgG Differentially Affected the Level of Expression of Common Monocyte Cell Surface Markers}

Freshly isolated monocytes were cultured for $48 \mathrm{~h}$ in the presence of IVIG, $\mathrm{Sia}^{-} \mathrm{IgG}$, or $\mathrm{Sia}^{+} \mathrm{IgG}$ and analyzed by flow cytometry for changes in staining intensity of common markers of monocyte differentiation and maturation. Briefly, we examined the expression of CD86, CD80, HLA-DR, dendric cell immunorecptor (DCIR), and dendritic cell-specific intercellular adhesion molecule-3-grabbing nonintegrin (DC-SIGN, also known as CD209). The latter two markers were chosen based on the concept that they are C-type lectin receptors. Both DCIR and DC-SIGN recognize distinct glycosylation patterns on IgG molecules, and binding interactions between these entities may influence immunomodulatory signaling [27]. Data obtained from a representative experiment are shown in Figure 1. There was a dose-dependent increase of CD80 expression when monocytes were treated with the $\mathrm{Sia}^{+}$fraction when compared to untreated (control) cultures, intact IVIG, or the $\mathrm{Sia}^{-}$fraction. Changes in expression of CD86, DC-SIGN (CD209), and DCIR were more modest, although many reached statistical significance. By contrast, HLA-DR expression was markedly increased in monocytes treated with intact IVIG and the $\mathrm{Sia}^{-}$fraction, whereas, the $\mathrm{Sia}^{+}$fraction was more comparable to control cultures.

\subsection{Sia+ IgG Increased Cytokine/Chemokine Production from Monocytes}

In order to evaluate the physiologic effects of IVIG and its fractions on monocytes, we measured selected cytokine/chemokine levels in cell culture supernatants obtained from the experiments described above. There were minimal differences in cytokine/chemokine production of monocytes treated with IVIG or its $\mathrm{Sia}^{-}$fraction when compared to control cultures (Figure 2). By contrast, treatment with $\mathrm{Sia}^{+} \mathrm{IgG}$ revealed a dose-dependent increase in secretion of IL-6, TNF $\alpha$, RANTES, IL-1 $\beta$, MCP-4, IL-10, and CXCL1. There were no significant differences in IL-2 concentrations among all treatment groups. The results indicated a profound augmentation of cytokine/chemokine production upon treatment of monocytes with $\mathrm{Sia}^{+} \mathrm{IgG}$. The $\mathrm{Sia}^{-}$fraction of IVIG, which represents the majority species (approx. 88\%) in intact IVIG, therefore, attenuated the effects of the $\mathrm{Sia}^{+}$fraction.

\subsection{Sia+ IgG Differentially Affected the Levels of Expression of Macrophage-Associated Surface Markers on Monocytes}

Macrophage populations have commonly been described as having inflammatory or anti-inflammatory/repairing phenotypes, referred to as M1 or M2, respectively. In order to evaluate whether IVIG or its $\mathrm{Sia}^{+}$and $\mathrm{Sia}^{-} \mathrm{frac}_{-}$ tions induced monocyte polarization towards either phenotype, we examined the expression of CD40 and CD64 as markers of the M1 subset, and CD163 and CD206 for the M2 subset. Figure 3 displays mean fluorescence intensity (MFI) values for cell surface marker expression. The expression of CD40 was significantly increased 

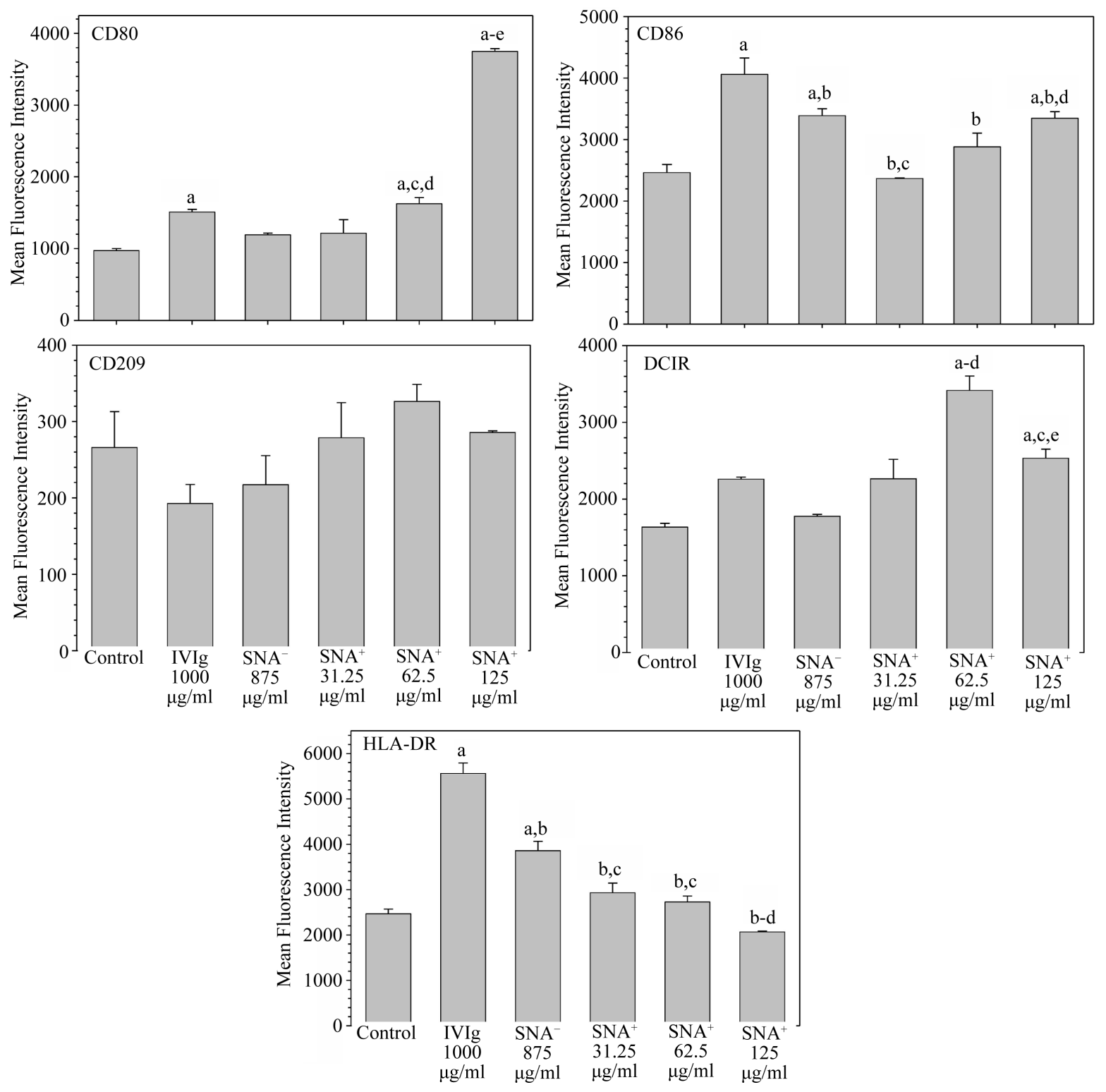

Figure 1. Expressionof monocyte-associated cell surface markers following treatment of monocytes with intact IVIG,

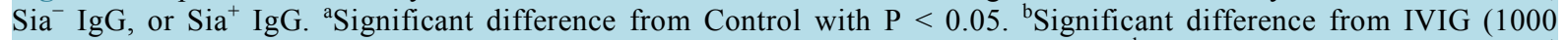
$\mu \mathrm{g} / \mathrm{mL})$ with $\mathrm{P}<0.05$. ${ }^{\mathrm{c}}$ Significant difference from $\mathrm{Sia}^{-}(875 \mu \mathrm{g} / \mathrm{mL})$ with $\mathrm{P}<0.05$. ${ }^{\mathrm{d}}$ Significant difference from Sia ${ }^{+}$ $(31.25 \mu \mathrm{g} / \mathrm{mL})$ with $\mathrm{P}<0.05$. ${ }^{\mathrm{e}}$ Significant difference from $\mathrm{Sia}^{+}(62.5 \mu \mathrm{g} / \mathrm{mL})$ with $\mathrm{P}<0.05$.

by treatment with $\mathrm{Sia}^{+} \mathrm{IgG}$ when compared to all other treatment groups. On the other hand, $\mathrm{Sia}^{+} \mathrm{IgG}$ dampened the expression of CD64. Treatment with $\mathrm{Sia}^{+} \mathrm{IgG}$ also augmented the expression of CD206, but had no significant effect on CD163 expression. The data suggest that $\mathrm{Sia}^{+} \mathrm{IgG}$ may influence the differentiation of monocytes towards a macrophage phenotype; however, there was no distinct preference towards the M1 or M2 lineage when assessed by these putative M1 and M2 markers.

\subsection{The Fraction of Monocytes That Express Macrophage-Associated Surface Markers Was Modulated by IVIG and Both $\mathrm{Sia}^{+}$and Sia- IgG Fractions}

We next determined the effect of IVIG and its different fractions on the expression markers of macrophage polarization directly on monocytes. To this end, we added IVIG or its SNA fractions to cultured monocytes for 48 $\mathrm{h}$ and examined the fraction of cells that expressed M1 and M2 markers (Table 1). The fraction of CD40 mo- 

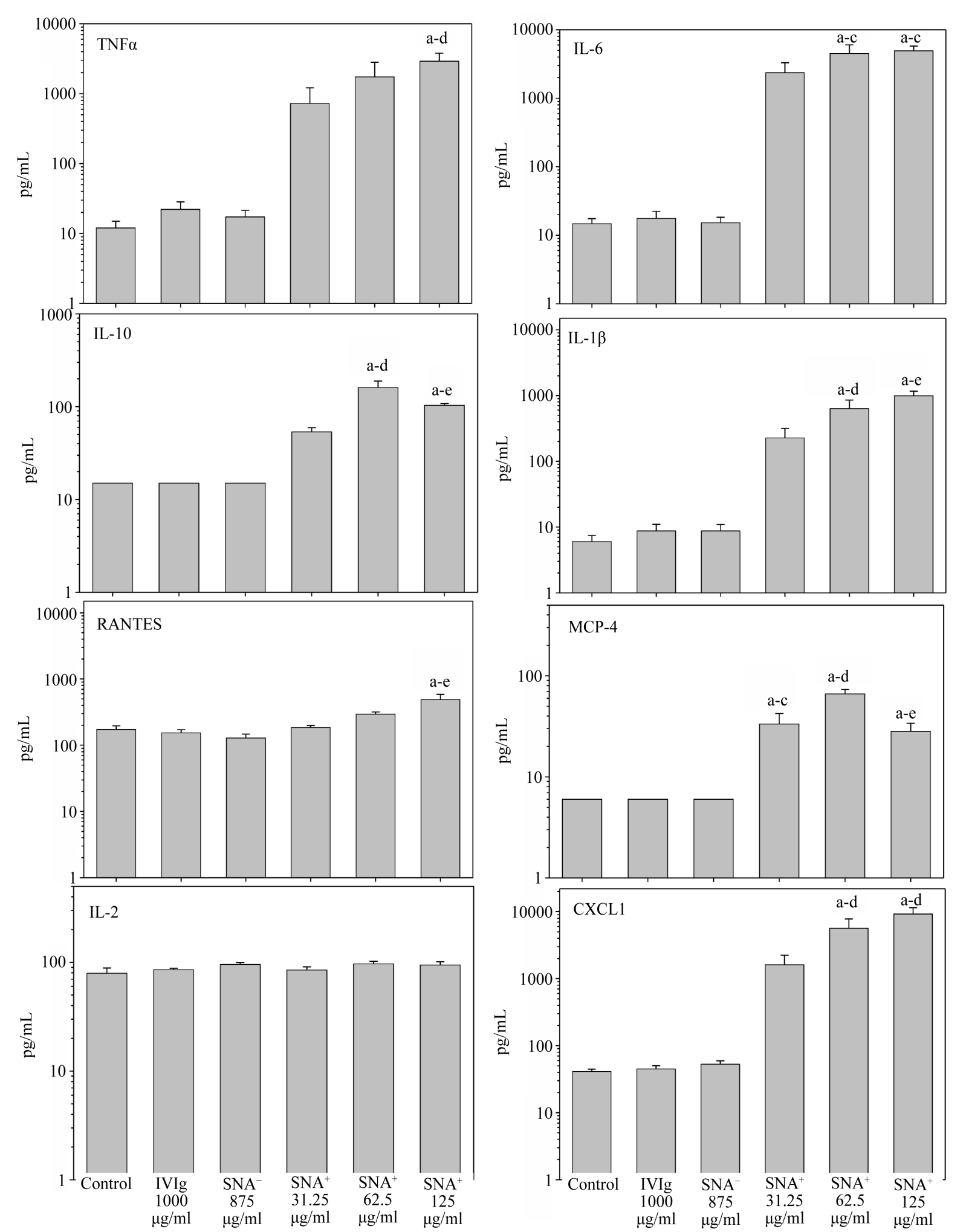

Figure 2. Expression of pro-inflammatory and anti-inflammatory cytokines/chemokines by monocytes cultured with

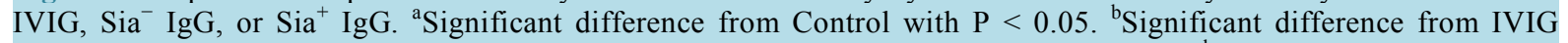
$(1000 \mu \mathrm{g} / \mathrm{mL})$ with $\mathrm{P}<0.05$. ${ }^{\mathrm{c}}$ Significant difference from Sia ${ }^{-}(875 \mu \mathrm{g} / \mathrm{mL})$ with $\mathrm{P}<0.05$. ${ }^{\mathrm{d}}$ Significant difference from $\mathrm{Sia}^{+}(31.25 \mu \mathrm{g} / \mathrm{mL})$ with $\mathrm{P}<0.05$. ${ }^{\mathrm{e}}$ Significant difference from $\mathrm{Sia}^{+}(62.5 \mu \mathrm{g} / \mathrm{mL})$ with $\mathrm{P}<0.05$. 

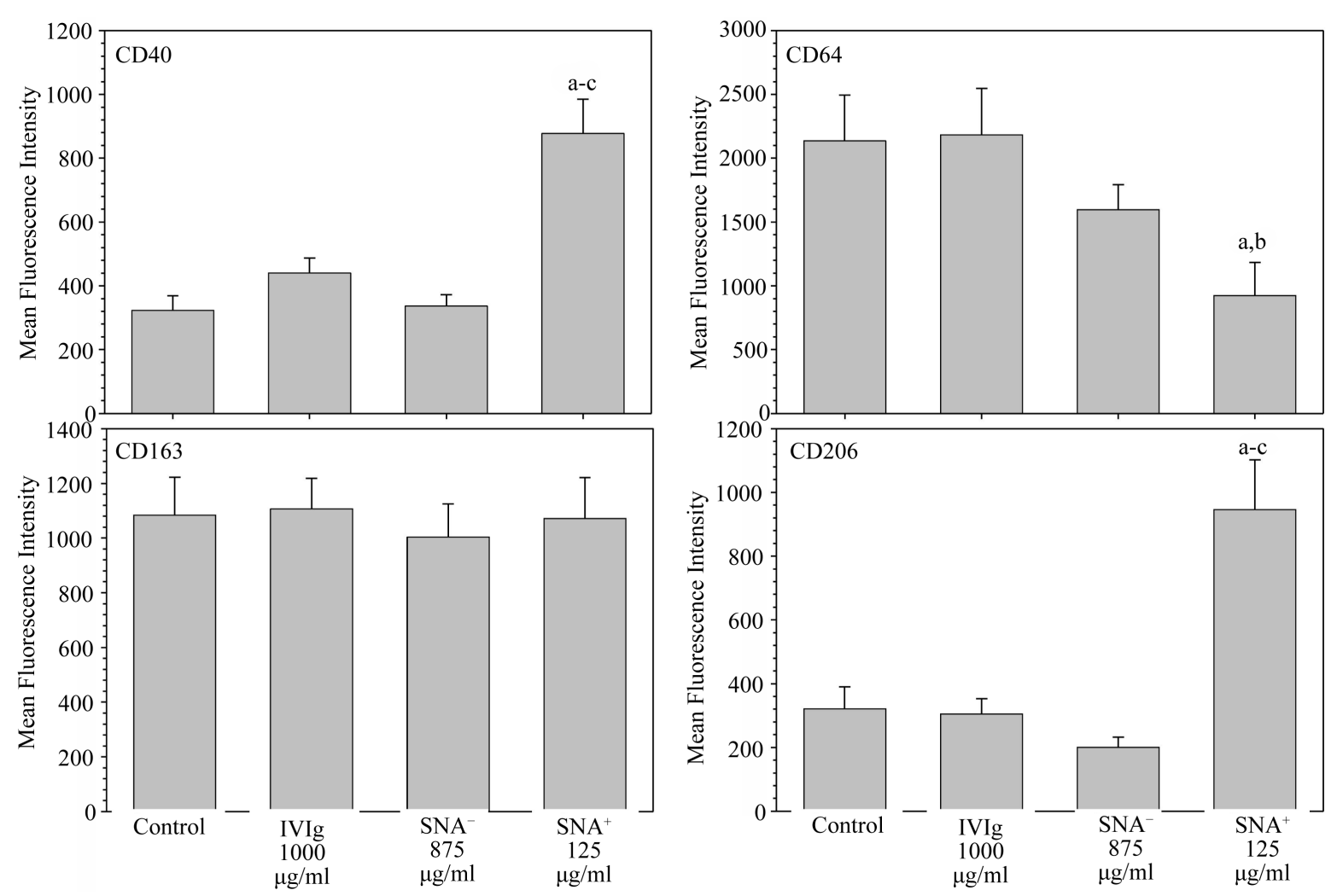

Figure 3. Expression of macrophage-associated cell surface markers following treatment of monocytes with intact

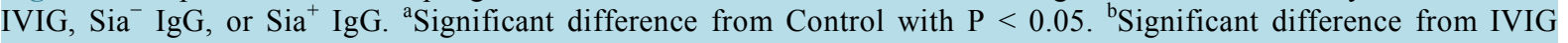
$(1000 \mu \mathrm{g} / \mathrm{mL})$ with $\mathrm{P}<0.05$. ${ }^{\mathrm{c} S i g n i f i c a n t}$ difference from $\mathrm{Sia}^{-}(875 \mu \mathrm{g} / \mathrm{mL})$ with $\mathrm{P}<0.05$.

Table 1. Percentage of cells staining positive for macrophage-associated markers on monocytes cultured with IVIG, $\mathrm{Sia}^{-} \mathrm{IgG}$, or $\mathrm{Sia}^{+} \mathrm{IgG}$.

\begin{tabular}{ccccc}
\hline & Control & IVIG $(\mathbf{1 0 0 0} \boldsymbol{\mu g} / \mathbf{m L})$ & $\mathbf{S i a}^{-}(\mathbf{8 7 5} \boldsymbol{\mu g} / \mathbf{m L})$ & $\mathbf{S i a}^{+}(\mathbf{1 2 5} \boldsymbol{\mu g} / \mathbf{m L})$ \\
\hline CD40 & $8.6 \pm 2.3$ & $22.4 \pm 5.3^{\mathrm{a}}$ & $17.8 \pm 4.3$ & $68.7 \pm 2.6^{\mathrm{a}-\mathrm{c}}$ \\
CD64 & $87.9 \pm 1.6$ & $88.0 \pm 2.0$ & $84.4 \pm 3.0$ & $83.8 \pm 0.6$ \\
CD163 & $3.7 \pm 0.8$ & $5.1 \pm 0.8$ & $3.8 \pm 0.4$ & $16.4 \pm 3.5^{\mathrm{a}-\mathrm{c}}$ \\
CD206 & $7.3 \pm 1.9$ & $7.0 \pm 1.9$ & $3.5 \pm 0.4$ & $50.4 \pm 4.5^{\mathrm{a}-\mathrm{c}}$ \\
\hline
\end{tabular}

a Significant difference from Control with $\mathrm{P}<0.05 .{ }^{\mathrm{b}}$ Significant difference from IVIG $(1000 \mu \mathrm{g} / \mathrm{mL})$ with $\mathrm{P}<0.05 .{ }^{\mathrm{c}}$ Significant difference from $\mathrm{Sia}^{-}(875 \mu \mathrm{g} / \mathrm{mL})$ with $\mathrm{P}<0.05$.

nocytes was modestly increased in response to IVIG and $\mathrm{Sia}^{-} \mathrm{IgG}$ when compared to control, whereas $\mathrm{Sia}^{+} \mathrm{IgG}$ induced a dramatic increase in the percentage of $\mathrm{CD}_{4} 0^{+}$monocytes. This mirrors the induction of surface levels of CD40 as measured by MFI as shown above. By contrast, we observed no change in the effect $\mathrm{Sia}^{+}$on the percentage of $\mathrm{CD} 4^{+}$cells. The fraction of cells expressing CD163 was increased by treatment with $\mathrm{Sia}^{+} \mathrm{IgG}$ when compared to all other treatments. In addition, the fraction of $\mathrm{CD} 206^{+}$cells was increased nearly seven-fold following treatment with $\mathrm{Sia}^{+} \mathrm{IgG}$. The results provide evidence that $\mathrm{Sia}^{+} \mathrm{IgG}$, as stated above, influenced the expression of macrophage-associated markers on monocytes, but without a clear relationship between markers associated with what have been described for conventional M1 and M2 phenotypes. Because of the more pronounced induction of CD40 and CD206 expression on monocytes treated with $\mathrm{Sia}^{+}$fraction of IgG, we analyzed the cells for dual expression of each marker in the flow cytometry panel. As shown in Table 2, the changes in most double-positive populations was only modest; however, when compared to untreated cells or cells treated with intact IVIG or the $\mathrm{Sia}^{-} \mathrm{IgG}$ fraction, the $\mathrm{Sia}^{+} \mathrm{IgG}$ fraction promoted a pronounced increase in the percen- 
Table 2. Percentage of cells staining double-positive for macrophage-associated cell surface markers on monocytes with IVIG, $\mathrm{Sia}^{-} \mathrm{IgG}$, or $\mathrm{Sia}^{+} \mathrm{IgG}$.

\begin{tabular}{ccccc}
\hline & Control & IVIG $(\mathbf{1 0 0 0} \boldsymbol{\mu g} / \mathbf{m L})$ & Sia $^{-}(\mathbf{8 7 5} \boldsymbol{\mu g} / \mathbf{m L})$ & Sia $^{+}(\mathbf{1 2 5} \boldsymbol{\mu g} / \mathbf{m L})$ \\
\hline $\mathbf{C D 4 0}^{+} \mathbf{C D 6 4}^{+}$ & $0.5 \pm 0.2$ & $1.5 \pm 0.4$ & $0.9 \pm 0.2$ & $0.3 \pm 0.1$ \\
$\mathbf{C D 4 0}^{+} \mathbf{C D 2 0 6}^{+}$ & $1.7 \pm 0.5$ & $3.6 \pm 0.9$ & $2.4 \pm 0.6$ & $32.8 \pm 1.8^{\mathrm{a}-\mathrm{c}}$ \\
$\mathbf{C D 4 0}^{+} \mathbf{C D 1 6 3}^{+}$ & $0.9 \pm 0.3$ & $1.6 \pm 0.9$ & $1.7 \pm 0.4$ & $3.1 \pm 0.8$ \\
$\mathbf{C D 6 4}^{+} \mathbf{C D 2 0 6}^{+}$ & $0.9 \pm 0.2$ & $2.9 \pm 0.8$ & $1.8 \pm 0.4$ & $0.3 \pm 0.1$ \\
$\mathbf{C D 6 4}^{+} \mathbf{C D 1 6 3}^{+}$ & $0.6 \pm 0.3$ & $1.5 \pm 0.6$ & $1.1 \pm 0.4$ & $0.4 \pm 0.2$ \\
$\mathbf{C D 1 6 3}^{+} \mathbf{C D 2 0 6}^{+}$ & $3.8 \pm 0.9$ & $6.4 \pm 1.7$ & $6.0 \pm 1.5$ & $4.5 \pm 1.1$ \\
\hline
\end{tabular}

${ }^{\mathrm{a}}$ Significant difference from Control with $\mathrm{P}<0.05$. ${ }^{\mathrm{b}}$ Significant difference from IVIG $(1000 \mu \mathrm{g} / \mathrm{mL})$ with $\mathrm{P}<0.05$. ${ }^{\mathrm{c}}$ Significant difference from $\mathrm{Sia}^{-}(875 \mu \mathrm{g} / \mathrm{mL})$ with $\mathrm{P}<0.05$.

tage of cells that stained for both CD40 and CD206 ( $<0.05$ ). Thus, nearly one-third of monocytes treated with $\mathrm{Sia}^{+}$IgG were double-positive for CD40 and CD206. This was an unanticipated finding, as CD40 and CD206 are more commonly referred to as M1 or M2 markers, respectively.

\subsection{Cell Surface Marker Expression on Cultured Macrophages Was Affected by Both $\mathrm{Sia}^{+}$IgG and $\mathrm{Sia}^{-} \mathrm{IgG}^{-}$}

We also examined the effects of IVIG and its fractions on M1 and M2 marker expression directly on macrophages generated from monocytes. Monocytes were first treated with M-CSF for six days, followed by $48 \mathrm{~h}$ treatment with IVIG, $\mathrm{Sia}^{+} \mathrm{IgG}$, and $\mathrm{Sia}^{-} \mathrm{IgG}$. As shown in Figure 4, the M1 markers (CD40 and CD64) were only modestly affected by IVIG and its SNA fractions, and these changes did not reach statistical significance. On the other hand, CD163 expression was significantly increased by treatment with $\mathrm{Sia}^{+} \mathrm{IgG}$ when compared to the control, IVIG, and $\mathrm{Sia}^{-} \mathrm{IgG}$ groups. Expression of CD206 was significantly increased by $\mathrm{Sia}^{-} \mathrm{IgG}^{-}$treatment when compared to the other treatment groups, while the $\mathrm{Sia}^{+}$fraction had a modest dampening effect on CD206 expression. These data suggest that $\mathrm{Sia}^{+} \mathrm{IgG}$ may push existing macrophages towards a M2 phenotype due to the increase in CD163 expression, but did not induce shifts to a M1 phenotype.

\subsection{The Fraction of Macrophages That Express Macrophage-Associated Cell Surface Markers Was Marginally Affected by Treatment with Sia ${ }^{+}$IgG}

Additional data from flow cytometric analyses of macrophages generated by M-CSF treatment of monocytes are shown in Table 3. None of the treatments had significant effects on the fraction of macrophages expressing the M1 markers CD40 and CD64, though IVIG treatment tended to decrease the percentage of CD64 ${ }^{+}$cells. Consistent with the induction of increased cell surface expression of CD163 on macrophages, $\mathrm{Sia}^{+} \mathrm{IgG}$ also increased the percentage of $\mathrm{CD} 63^{+}$cells when compared to all other treatments. In addition, the percentage of cells expressing CD163 was decreased by IVIG treatment when compared to the Control group, although this did not reach statistical significance. Although none of the treatments affected the fraction of $\mathrm{CD}^{2} 06^{+}$cells when compared to control, values for the $\mathrm{Sia}^{+} \mathrm{IgG}$ treatment were reduced when compared to the $\mathrm{Sia}^{-}$treatment.

\subsection{Sia+IgG Induced Profound Increases in Cytokine/Chemokine Production in Macrophages}

In order to assess the effects of IVIG and its fractions on pro-inflammatory and anti-inflammatory cytokine/ chemokine production, M-CSF macrophages were treated with IVIG or its fractions for $48 \mathrm{~h}$. The concentrations of TNF $\alpha$, IL-6, CXCL1, RANTES, and IL10 were significantly increased following treatment with $\mathrm{Sia}^{+}$IgG when compared to all other treatments (Figure 5). Among the more profound changes, these represented an over 10-fold increase for TNF $\alpha$ to over a 30 -fold induction for CXCL1 when compared to intact IVIG alone. IVIG exerted a small, but significant dampening of constitutive secretion of MCP-4, but this was paradoxically reversed with the $\mathrm{Sia}^{-}$and $\mathrm{Sia}^{+}$IgG fractions. There were small increases in IL-2 secretion following treatment 

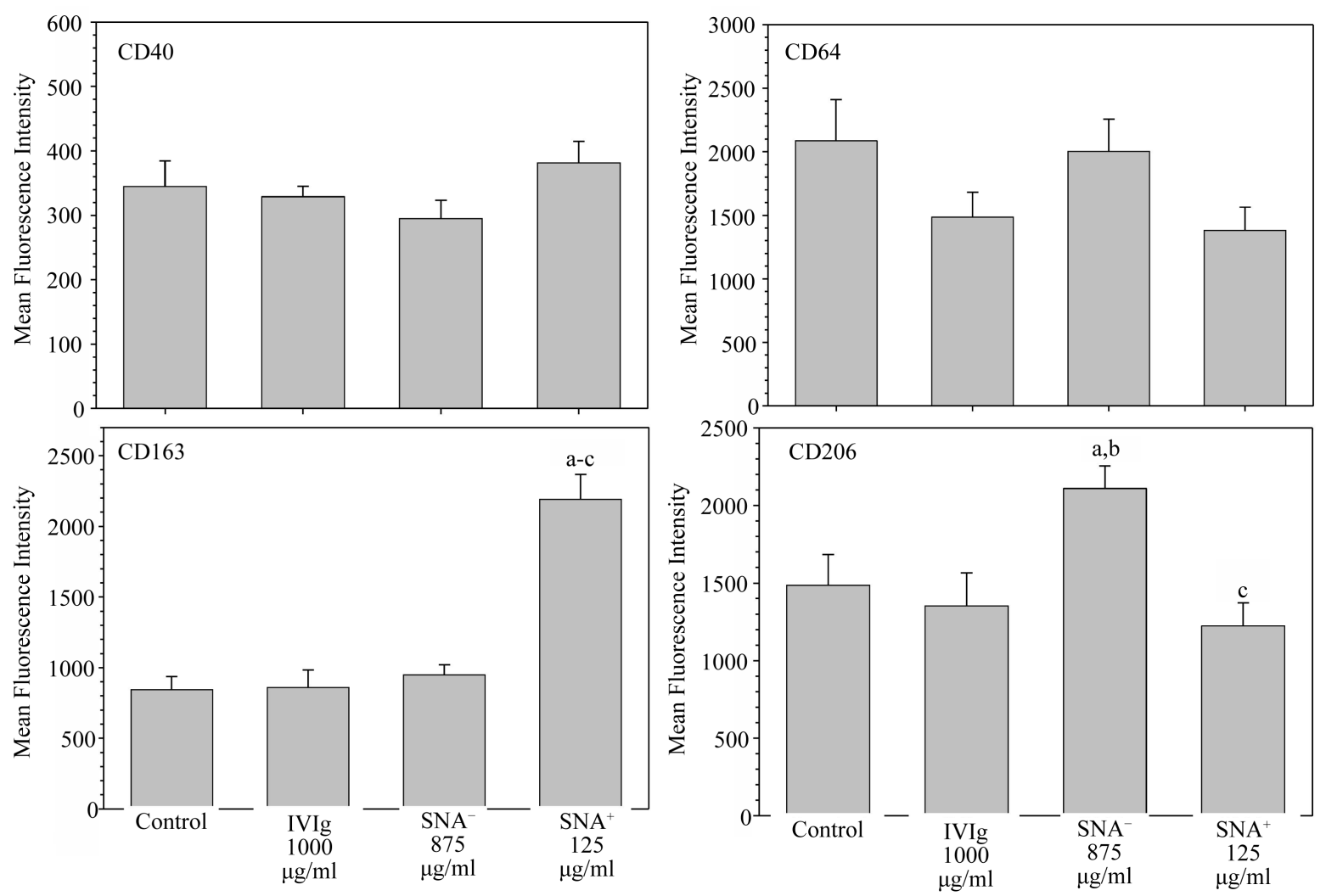

Figure 4. Expression of macrophage-associated cell surface markers on macrophages following treatment with intact IVIG, $\mathrm{Sia}^{-} \mathrm{IgG}$, or $\mathrm{Sia}^{+} \mathrm{IgG}$ as determined by flow cytometry. ${ }^{\mathrm{a}}$ Significant difference from Control with $\mathrm{P}<0.05$. ${ }^{\text {b }} \mathrm{Sig}-$ nificant difference from IVIG $(1000 \mu \mathrm{g} / \mathrm{mL})$ with $\mathrm{P}<0.05$. ${ }^{\mathrm{c}}$ Significant difference from $\mathrm{SIA}^{-}(875 \mu \mathrm{g} / \mathrm{mL})$ with $\mathrm{P}<$ 0.05 .

Table 3. Percentage of cells staining positive for macrophage-associated markers on macrophages cultured with IVIG, $\mathrm{Sia}^{-} \mathrm{IgG}$, or $\mathrm{Sia}^{+} \mathrm{IgG}$.

\begin{tabular}{ccccc}
\hline & Control & IVIG $(\mathbf{1 0 0 0} \boldsymbol{\mu g} / \mathbf{m L})$ & Sia $^{-}(\mathbf{8 7 5} \boldsymbol{\mu g} / \mathbf{m L})$ & $\mathbf{S i a}^{+}(\mathbf{1 2 5} \boldsymbol{\mu g} / \mathbf{m L})$ \\
CD40 & $6.7 \pm 2.7$ & $5.3 \pm 1.3$ & $4.2 \pm 2.0$ & $7.1 \pm 1.4$ \\
CD64 & $65.9 \pm 9.0$ & $31.7 \pm 7.3$ & $47.0 \pm 9.8$ & $54.4 \pm 8.1$ \\
CD163 & $24.0 \pm 2.9$ & $10.7 \pm 2.6$ & $16.6 \pm 3.6$ & $55.7 \pm 4.8^{\mathrm{a}-\mathrm{c}}$ \\
CD206 & $49.4 \pm 4.0$ & $41.1 \pm 3.4$ & $56.4 \pm 2.9$ & $43.6 \pm 4.6^{\mathrm{c}}$ \\
\hline
\end{tabular}

${ }^{a}$ Significant difference from Control with $\mathrm{P}<0.05$. ${ }^{\mathrm{b}}$ Significant difference from IVIG $(1000 \mu \mathrm{g} / \mathrm{mL})$ with $\mathrm{P}<0.05$. ${ }^{\mathrm{c}}$ Significant difference from $\operatorname{SIA}^{-}(875 \mu \mathrm{g} / \mathrm{mL})$ with $\mathrm{P}<0.05$.

with $\mathrm{Sia}^{+} \mathrm{IgG}$ when compared to the other treatments. $\mathrm{Sia}^{+} \mathrm{IgG}$ treatment also induced a small but significant decrease in TGF- $\beta 1$ concentrations versus all other treatments. Interestingly, we were unable to detect any appreciable amounts of IL-4 in the cell supernatants examined (data not shown). As in monocytes, $\mathrm{Sia}^{+}$IgG induced the production of numerous inflammatory cytokines/chemokines in macrophages; however, $\mathrm{Sia}^{+}$IgG also augmented the production of the anti-inflammatory cytokine IL-10.

\section{Discussion}

The present study examined the differential effects of $\mathrm{Sia}^{+} \mathrm{IgG}$ on cell surface marker expression and cytokine/chemokine secretion in monocytes from PBMC and monocyte-derived macrophages. We found that both of these cell types were differentially affected by treatment with the $\mathrm{Sia}^{+}$and $\mathrm{Sia}^{-}$glycoforms of IgG. Treatment of 

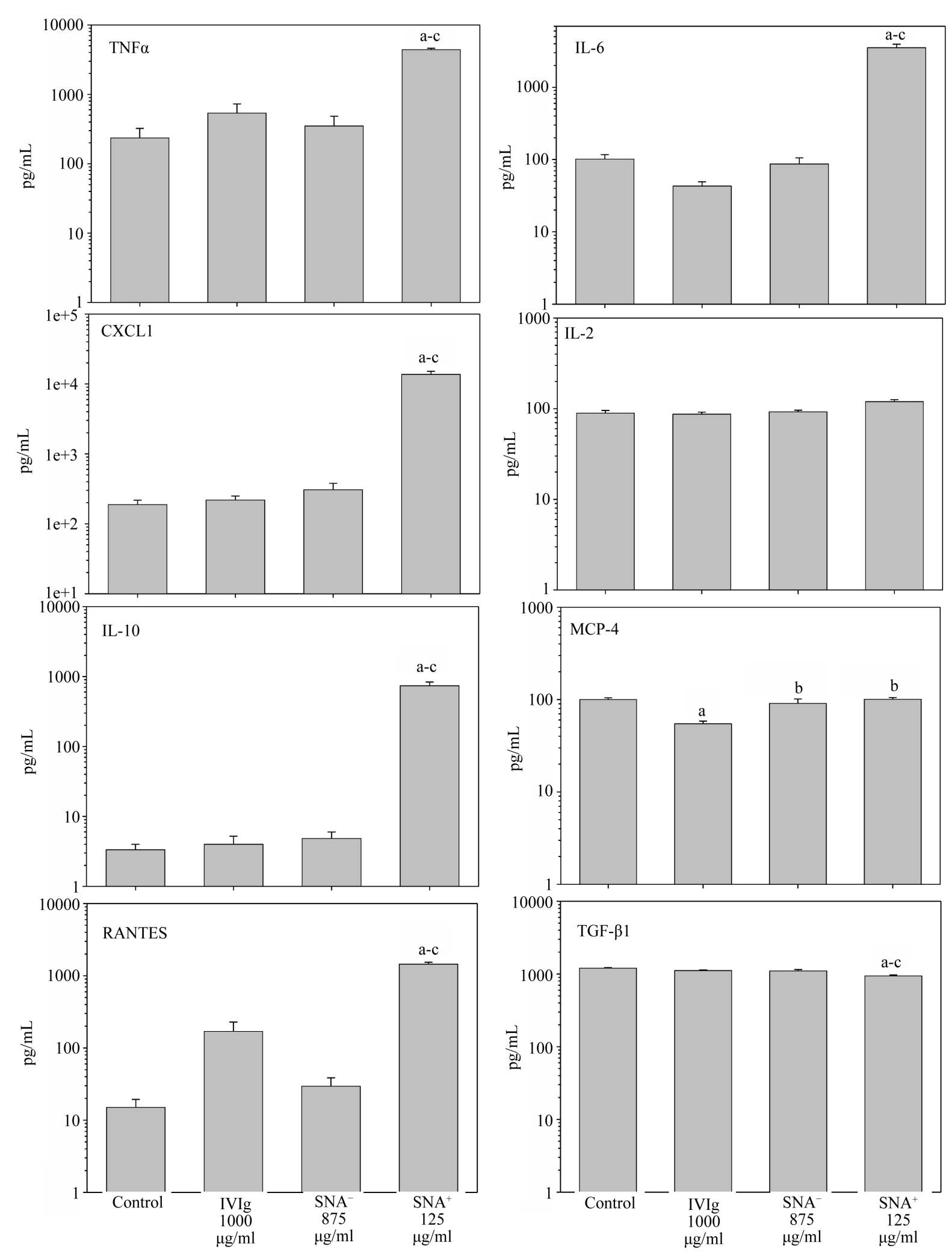

Figure 5. Expression of pro-inflammatory and anti-inflammatory cytokines/chemokines by macrophages cultured with IVIG, Sia ${ }^{-} \mathrm{IgG}$, or $\mathrm{Sia}^{+}$IgG. ${ }^{\mathrm{a}}$ Significant difference from Control with $\mathrm{P}<0.05$. ${ }^{\mathrm{b}}$ Significant difference from IVIG (1000 $\mu \mathrm{g} / \mathrm{mL})$ with $\mathrm{P}<0.05$. ${ }^{\mathrm{c}}$ Significant difference from $\mathrm{Sia}^{-}(875 \mu \mathrm{g} / \mathrm{mL})$ with $\mathrm{P}<0.05$. 
monocytes with $\mathrm{Sia}^{+} \mathrm{IgG}$ elicited only a few minor changes in expression of cell surface markers and the fraction of cells that expressed specific activation markers. On the other hand, cytokine/chemokine production from monocytes was greatly affected by the presence of $\mathrm{Sia}^{+} \mathrm{IgG}$, especially when compared to the effects initiated by intact IVIG or the SNA ${ }^{-}$fraction of IVIG. $\mathrm{Sia}^{+} \mathrm{IgG}$ also induced expression of CD163 on macrophages, and the production of cytokine/chemokines by macrophages was significantly increased in the presence of $\mathrm{Sia}^{+} \mathrm{IgG}$. The results support the hypothesis that $\mathrm{Sia}^{+} \mathrm{IgG}$ exerts significant and differential effects on other cells of the immune system, in this case, monocytes and macrophages. It is interesting to note that $\mathrm{Sia}^{+} \mathrm{IgG}$ induces distinct, yet overlapping, cytokine/chemokine responses in monocytes and macrophages. For example, $\mathrm{Sia}^{+} \mathrm{IgG}$ dramatically enhances the production of TNF $\alpha$, IL- 6 . IL-1 $\beta$, MCP-4 and CXCL1 by monocytes, but not RANTES or IL-10. By contrast, macrophages show more modest changes in TNF $\alpha$, IL-6, and RANTES production, no change in MCP-4 secretion, and dramatic (nearly 300-fold) increases in IL-10 expression. Overall, the patterns of cytokines produced in response to the $\mathrm{Sia}^{+} \mathrm{IgG}$ fraction were reminiscent of those produced in response to immune complexes [19] [28] namely, enhanced secretion of IL-1, IL-6, IL-10, and TNF, and decreased expression of IL-12 and TGF- $\beta$. Overall, this pattern is most consistent with a phenotype of the M2b macrophage which is associated with Th2 activation and immunoregulation [29]. When taken together, the data support the concept that IgG effector function is profoundly influenced by post-translational glycosylation, and that it is possible to dissect out distinctive phenotypic effects on cells involved in the inflammatory and tissue healing processes. These distinct effects are mediated through different glycoforms of IgG contained within IVIG.

The initial use of IVIG as an antibody replacement therapy has changed over the years, and it is now commonly used to treat a variety of inflammatory diseases including idiopathic thrombocytopenia purpura, GuillainBarre syndrome, Kawasaki's disease, and chronic inflammatory demyelinating neuropathy [30]-[32]. It is also used for treatment of allograft rejection of solid organs [33] [34], as well as in antibody reduction protocols for patients awaiting transplantation due to high levels of antibodies to HLA antigens [35]. The exact mechanism(s) of action of the anti-inflammatory properties of IVIG have been the subject of debate; but the emerging notion from the Ravetch group's body of work is that the anti-inflammatory activity within IVIG resides within a small population of immunoglobulins with $\mathrm{Fc}$ glycans that terminate in $\alpha 2,6 \mathrm{Sia}$ [8]. In support of this, depletion of terminally-sialylatedglycans from IVIG by SNA lectin chromatography eliminates the anti-inflammatory effects of IVIG in a variety of animal and ex-vivo models, and enzymatically engineered IgG1 Fc that is highly sialylated recapitulates the anti-inflammatory actions of IVIG [36]-[38]. Furthermore, these sialylated immunoglobulins appear to exert their effects via the specific C-type lectin, DC-SIGN, expressed on cells of the monocyte/ macrophage/dendritic cell series [39]. Sia ${ }^{+}$IgG may also exert effects via interaction with DCIR [27] and CD23 [8] [40]; thus, sialylated IgG may serve as a functionally robust ligand that acts at the level of multiple receptors and promotes anti-inflammatory functions and phenotypes among monocytes, monocyte-derived dendritic cells, and macrophages.

Although numerous studies support the role of Fc sialylation being responsible for the anti-inflammatory properties of IVIG, the involvement of $\mathrm{Sia}^{+} \mathrm{F}\left(\mathrm{ab}^{\prime}\right) 2$ is also supported [41] [42]. For example, Kaeserman and co-workers reported that removal of Sia from $\mathrm{F}(\mathrm{ab}$ ')2 fragments led to loss of anti-inflammatory activity [43]. In addition, Guhr and colleagues reported that enrichment of $\mathrm{Sia}^{+} \mathrm{F}\left(\mathrm{ab}^{\prime}\right) 2$ glycans resulted in a reduction of the anti- inflammatory activity in a mouse model of ITP [44]. Because sialylated Fab fragments outnumber Fc fragments in IgG by nearly 10-fold [5], a more precise description of the roles of $\mathrm{Sia}^{+} \mathrm{Fc}$ and $\mathrm{F}\left(\mathrm{ab}^{\prime}\right) 2$ in IVIG preparations will require advances in our ability to separate the two species beyond what is achievable by simple SNA lectin fractionation.

We have previously shown that $\mathrm{Sia}^{+} \mathrm{IgG}$ was able to modulate the maturation and differentiation of human DC [21]. We chose to examine monocytes (a mixed population of DC precursors) and macrophages (distinct lineage) in the present study. Monocytes play multiple roles in immune function besides giving rise to DC and macrophages, including antigen presentation, phagocytosis, and cytokine production. The ability of $\mathrm{Sia}^{+} \operatorname{IgG}$ to modulate surface maker expression and cytokine production on monocytes did not replicate any known findings. Macrophages, the professional phagocytes found in tissues of all types, have been historically assigned as either being pro-inflammatory (M1) or anti-inflammatory (M2) [45]. More recent opinions on macrophage differentiation and function rely less on stable phenotypic subsets and more on pathways that interact to comprise complex and mixed phenotypes [17] [19] [46]. These concepts question the simple binary M1/M2 macrophage designations, and rather assign macrophage function to specific stimuli.

While the use of IVIG has dramatically expanded over the last few decades, its use has been somewhat li- 
mited because of its expense and a history of shortages in supply [47]. Because the majority of the anti-inflammatory properties of IVIG appear to reside in the $\mathrm{Sia}^{+}$fraction, shown herein and in a variety of other experimental models, van Gent and Kwekkeboom [48] have proposed that lectin fractionation during the manufacturing of IVIG could make available two pools of IgG, one ( $\mathrm{Sia}^{+}$) with anti-inflammatory properties, the other (polyclonal $\mathrm{Sia}^{-} \mathrm{IgG}$ ) for IgG supplementation in antibody deficient patients. We think that this is a novel solution to the IVIG shortage and is supported by our findings of a functional dichotomy of IVIG based on glycans that terminate in Sia. In addition, because many of the properties of $\mathrm{Sia}^{+}$described here were masked by the effects of the $\mathrm{Sia}^{-}$fraction, continued exploration of the use of purified forms ( $\mathrm{Sia}^{+}$fractions of IVIG, or highly sialylated $\mathrm{IgG}$ produced by recombinant or enzymatic modifications of total $\mathrm{IgG}$ ) is warranted.

\section{Acknowledgements}

This work was supported by a grant (\#570-3673) from the Department of Cardiovascular Surgery at Aurora St. Luke's Medical Center, Milwaukee, WI.

\section{Conflicts of Interest}

The authors declare no competing financial interests.

\section{References}

[1] Kaneko, Y., Nimmerjahn, F. and Ravetch, J.V. (2006) Anti-Inflammatory Activity of Immunoglobulin G Resulting from Fc Sialylation. Science, 313, 670-673. http://dx.doi.org/10.1126/science.1129594

[2] Nimmerjahn, F. and Ravetch, J.V. (2010) Antibody-Mediated Modulation of Immune Responses. Immunological Reviews, 236, 265-275. http://dx.doi.org/10.1111/j.1600-065X.2010.00910.x

[3] Anthony, R.M. and Ravetch, J.V. (2010) A Novel Role for the IgG Fc Glycan: The Anti-Inflammatory Activity of Sialylated IgG Fcs. Journal of Clinical Immunology, 30, S9- S14. http://dx.doi.org/10.1007/s10875-010-9405-6

[4] Anthony, R.M., Wermeling, F. and Ravetch, J.V. (2012) Novel Roles for the IgG Fc Glycan. Annals of the New York Academy of Sciences, 1253, 170-180. http://dx.doi.org/10.1111/j.1749-6632.2011.06305.x

[5] Stadlmann, J., Weber, A., Pabst, M., et al. (2009) A Close Look at Human IgG Sialylation and Subclass Distribution after Lectin Fractionation. Proteomics, 9, 4143-4153. http://dx.doi.org/10.1002/pmic.200800931

[6] Boruchov, A.M., Heller, G., Veri, M.C., Bonvini, E., Ravetch, J.V. and Young, J.W. (2005) Activating and Inhibitory IgG Fc Receptors on Human DCs Mediate Opposing Functions. Journal of Clinical Investigation, 115, $2914-2923$. http://dx.doi.org/10.1172/JCI24772

[7] Nimmerjahn, F. and Ravetch, J.V. (2007) Antibodies, Fc Receptors and Cancer. Current Opinion in Immunology, 19, 239-245. http://dx.doi.org/10.1016/j.coi.2007.01.005

[8] Sondermann, P., Pincetic, A., Maamary, J., Lammens, K. and Ravetch, J.V. (2013) General Mechanism for Modulating Immunoglobulin Effector Function. Proceedings of the National Academy of Sciences of the United States of America, 110, 9868-9872. http://dx.doi.org/10.1073/pnas.1307864110

[9] Geissmann, F. (2007) The Origin of Dendritic Cells. Nature Immunology, 8, 558-560. http://dx.doi.org/10.1038/ni0607-558

[10] Geissmann, F., Manz, M.G., Jung, S., Sieweke, M.H., Merad, M. and Ley, K. (2010) Development of Monocytes, Macrophages, and Dendritic Cells. Science, 327, 656-661. http://dx.doi.org/10.1126/science.1178331

[11] Geissmann, F., Auffray, C., Palframan, R., et al. (2008) Blood Monocytes: Distinct Subsets, How They Relate to Dendritic Cells, and Their Possible Roles in the Regulation of T-Cell Responses. Immunology \& Cell Biology, 86, 398-408. http://dx.doi.org/10.1038/icb.2008.19

[12] Randolph, G.J., Beaulieu, S., Lebecque, S., Steinman, R.M. and Muller, W.A. (1998) Differentiation of Monocytes into Dendritic Cells in a Model of Transendothelial Trafficking. Science, 282, 480-483. http://dx.doi.org/10.1126/science.282.5388.480

[13] Geissmann, F., Gordon, S., Hume, D.A., Mowat, A.M. and Randolph, G.J. (2010) Unravelling Mononuclear Phagocyte Heterogeneity. Nature Reviews Immunology, 10, 453-460. http://dx.doi.org/10.1038/nri2784

[14] Auffray, C., Sieweke, M.H. and Geissmann, F. (2009) Blood Monocytes: Development, Heterogeneity, and Relationship with Dendritic cells. Annual Review of Immunology, 27, 669-692. http://dx.doi.org/10.1146/annurev.immunol.021908.132557

[15] Sica, A., Larghi, P., Mancino, A., et al. (2008) Macrophage Polarization in Tumour Progression. Seminars in Cancer 
Biology, 18, 349-355. http://dx.doi.org/10.1016/j.semcancer.2008.03.004

[16] Sica, A. and Mantovani, A. (2012) Macrophage Plasticity and Polarization: In Vivo Veritas. Journal of Clinical Investigation, 122, 787-795. http://dx.doi.org/10.1172/JCI59643

[17] Murray, P.J., Allen, J.E., Biswas, S.K., et al. (2014) Macrophage Activation and Polarization, Nomenclature and Experimental Guidelines. Immunity, 41, 14-20. http://dx.doi.org/10.1016/j.immuni.2014.06.008

[18] Italiani, P. and Boraschi, D. (2014) From Monocytes to M1/M2 Macrophages, Phenotypical vs. Functional Differentiation. Frontiers in Immunology, 5, 514. http://dx.doi.org/10.3389/fimmu.2014.00514

[19] Martinez, F.O. and Gordon, S. (2014) The M1 and M2 Paradigm of Macrophage Activation, Time for Reassessment. F1000Prime Reports, 6, 13. http://dx.doi.org/10.12703/P6-13

[20] Oaks, M., Taylor, S. and Shaffer, J. (2013) Autoantibodies Targeting Tumor-Associated Antigens in Metastatic Cancer, Sialylated IgGs as Candidate Anti-Inflammatory Antibodies. OncoImmunology, 2, e24841. http://dx.doi.org/10.4161/onci.24841

[21] Oaks, M., Rein, N., Richards, J.O. and Shaffer, J. (2014) Autoantibodies to the NY-ESO-1 Tumor Antigen in Metastatic Melanoma, Sialylation of the Fc Region of Immunoglobulin G Induces Differential Expression Signatures of Inflammatory Molecules during Dendritic Cell Differentiation and Maturation. Journal of Patient-Centered Research and Reviews, 1, 171-187. http://dx.doi.org/10.17294/2330-0698.1038

[22] Nimmerjahn, F. and Ravetch, J.V. (2008) Anti-Inflammatory Actions of Intravenous Immunoglobulin. Annual Review of Immunology, 26, 513-533. http://dx.doi.org/10.1146/annurev.immunol.26.021607.090232

[23] Ambarus, C.A., Krausz, S., van Eilk, M., et al. (201) Systematic Validation of Specific Phenotypic Markers for in Vitro Polarized Human Macrophages. Journal of Immunological Methods, 375, 196-206. http://dx.doi.org/10.1016/j.jim.2011.10.013

[24] Mosser, D.M. (2003) The Many Faces of Macrophage Activation. Journal of Leukocyte Biology, 73, $209-212$. http://dx.doi.org/10.1189/jlb.0602325

[25] Mosser, D.M. and Edwards, J.P. (2008) Exploring the Full Spectrum of Macrophage Activation. Nature Reviews Immunology, 8, 958-969. http://dx.doi.org/10.1038/nri2448

[26] Porcheray, F., Viaud, S., Rimaniol, A.C., et al. (2005) Macrophage Activation Switching: An Asset for the Resolution of Inflammation. Clinical \& Experimental Immunology, 142, 481-489. http://dx.doi.org/10.1111/j.1365-2249.2005.02934.x

[27] Garcia-Vallejo, J.J., Bloem, K., Knippels, L.M., Garssen, J., van Vliet, S.J. and van Kooyk, Y. (2015) The Consequences of Multiple Simultaneous C-Type Lectin-Ligand Interactions, DCIR Alters the Endo-Lysosomal Routing of DC-SIGN. Frontiers in Immunology, 6, 87. http://dx.doi.org/10.3389/fimmu.2015.00087

[28] Foey, A.D. (2015) Macrophage Polarization: A Collaboration of Differentiation, Activation, and Pre-Programming? Clinical and Cellular Immunology, 6, 293-308. http://dx.doi.org/10.4172/2155-9899.1000293

[29] Mantovani, A., Sica, A., Sozzani, S., Allavena, P., Vecchi, A. and Locati, M. (2004) The Chemokine System in Diverse Forms of Macrophage Activation and Polarization. Trends in Immunology, 25, 677-686. http://dx.doi.org/10.1016/j.it.2004.09.015

[30] Katz, U., Achiron, A., Sherer, Y. and Shoenfeld, Y. (2007) Safety of Intravenous Immunoglobulin (IVIG) Therapy. Autoimmunity Reviews, 6, 257-259. http://dx.doi.org/10.1016/j.autrev.2006.08.011

[31] Katz, U., Shoenfeld, Y. and Zandman-Goddard, G. (2011) Update on Intravenous Immunoglobulins (IVIg) Mechanisms of Action and Off- Label Use in Autoimmune Diseases. Current Pharmaceutical Design, 17, 3166-3175. http://dx.doi.org/10.2174/138161211798157540

[32] Baerenwaldt, A., Biburger, M. and Nimmerjahn, F. (2010) Mechanisms of Action of Intravenous Immunoglobulins. Expert Review of Clinical Immunology, 6, 425-434. http://dx.doi.org/10.1586/eci.10.9

[33] Jordan, S.C., Vo, A.A., Tyan, D., Nast, C.C. and Toyoda, M. (2005) Current Approaches to Treatment of Antibody-Mediated Rejection. Pediatric Transplantation, 9, 408-415. http://dx.doi.org/10.1111/j.1399-3046.2005.00363.x

[34] Jordan, S.C., Vo, A.A., Toyoda, M., Tyan, D. and Nast, C.C. (2005) Post-Transplant Therapy with High-Dose Intravenous Gammaglobulin, Applications to Treatment of Antibody-Mediated Rejection. Pediatric Transplantation, 9, 155-161. http://dx.doi.org/10.1111/j.1399-3046.2005.00256.x

[35] Jordan, S.C., Vo, A.A., Peng, A., Toyoda, M. and Tyan, D. (2006) Intravenous Gammaglobulin (IVIG): A Novel Approach to Improve Transplant Rates and Outcomes in Highly HLA-Sensitized Patients. American Journal of Transplantation, 6, 459-466. http://dx.doi.org/10.1111/j.1600-6143.2005.01214.x

[36] Anthony, R.M., Nimmerjahn, F., Ashline, D.J., Reinhold, V.N., Paulson, J.C. and Ravetch, J.V. (2008) Recapitulation of IVIG Anti-Inflammatory Activity with a Recombinant IgG Fc. Science, 320, 373-376. http://dx.doi.org/10.1126/science.1154315 
[37] Ahmed, A.A., Giddens, J., Pincetic, A. et al. (2014) Structural Characterization of Anti-Inflammatory Immunoglobulin G Fc Proteins. Journal of Molecular Biology, 426, 3166-3179. http://dx.doi.org/10.1016/j.jmb.2014.07.006

[38] Lin, C.W., Tsai, M.H., Li, S.T., et al. (2015) A Common Glycan Structure on Immunoglobulin G for Enhancement of Effector Functions. Proceedings of the National Academy of Sciences of the United States of America, 112, 1061110616. http://dx.doi.org/10.1073/pnas.1513456112

[39] Anthony, R.M., Wermeling, F., Karlsson, M.C. and Ravetch, J.V. (2008) Identification of a Receptor Required for the Anti-Inflammatory Activity of IVIG. Proceedings of the National Academy of Sciences of the United States of America, 105, 19571-19578. http://dx.doi.org/10.1073/pnas.0810163105

[40] Fiebiger, B.M., Maamary, J., Pincetic, A. and Ravetch, J.V. (2015) Protection in Antibody- and T Cell-Mediated Autoimmune Diseases by Antiinflammatory IgG Fcs Requires type II FcRs. Proceedings of the National Academy of Sciences of the United States of America, 112, E2385-E2394. http://dx.doi.org/10.1073/pnas.1505292112

[41] Schwab, I. and Nimmerjahn, F. (2014) Role of Sialylation in the Anti-Inflammatory Activity of Intravenous Immunoglobulin-F(ab')(2) versus Fc Sialylation. Clinical and Experimental Immunology, 178, 97-99. http://dx.doi.org/10.1111/cei.12527

[42] van de Bovenkamp, F.S., Hafkenscheid, L., Rispens, T. and Rombouts, Y. (2016) The Emerging Importance of IgG Fab Glycosylation in Immunity. The Journal of Immunology, 196, 1435-1441. http://dx.doi.org/10.4049/jimmunol.1502136

[43] Kasermann, F., Boerema, D.J., Ruegsegger, M., et al. (2012) Analysis and Functional Consequences of Increased Fab-Sialylation of Intravenous Immunoglobulin (IVIG) after Lectin Fractionation. PLoS ONE, 7, e37243. http://dx.doi.org/10.1371/journal.pone.0037243

[44] Guhr, T., Bloem, J., Derksen, N.I. et al. (2011) Enrichment of Sialylated IgG by Lectin Fractionation Does Not Enhance the Efficacy of Immunoglobulin G in a Murine Model of Immune Thrombocytopenia. PLoS ONE, 6, e21246. http://dx.doi.org/10.1371/journal.pone.0021246

[45] Mills, C.D., Kincaid, K., Alt, J.M., Heilman, M.J. and Hill, A.M. (2000) M-1/M-2 Macrophages and the Th1/Th2 Paradigm. The Journal of Immunology, 164, 6166-6173. http://dx.doi.org/10.4049/jimmunol.164.12.6166

[46] Murray, P.J. and Wynn, T.A. (2011) Obstacles and Opportunities for Understanding Macrophage Polarization. Journal of Leukocyte Biology, 89, 557-563. http://dx.doi.org/10.1189/jlb.0710409

[47] Pondrom, S. (2014) The IVIg Dilemma. American Journal of Transplantation, 14, 2195-2196. http://dx.doi.org/10.1111/ajt.12995

[48] Van Gent, R. and Kwekkeboom, J. (2015) The IVIg Dilemma: A Way Out? American Journal of Transplantation, 15, 1725-1726. http://dx.doi.org/10.1111/ajt.13253 